\title{
Nurses' Perceptions of Patient Care Continuity in Day Surgery
}

\section{Renholm, Marja}

2017-12

Renholm , M , Suominen , T , Puukka , P \& Leino-Kilpi , H 2017 , ' Nurses' Perceptions of

Patient Care Continuity in Day Surgery ' , Journal of PeriAnesthesia Nursing , vol. 32 , no. 6 , pp. 609-618 . https://doi.org/10.1016/j.jopan.2015.08.013

http://hdl.handle.net/10138/298169

https://doi.org/10.1016/j.jopan.2015.08.013

publishedVersion

Downloaded from Helda, University of Helsinki institutional repository.

This is an electronic reprint of the original article.

This reprint may differ from the original in pagination and typographic detail.

Please cite the original version. 


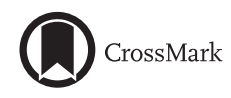

\title{
Nurses' Perceptions of Patient Care Continuity in Day Surgery
}

\author{
Marja Renbolm, PbD, RN, MNSc, Tarja Suominen, PbD, RN, Pauli Puukka, MSocSc, \\ Helena Leino-Kilpi, PbD, $R N$
}

\begin{abstract}
Purpose: The increase in day surgery has brought about a significant change in patient care and care continuity. The purpose of this study was to analyze nurses' perceptions of the realization of continuity of care in day surgery. Continuity of care is examined from the perspectives of time, flow, co-ordination flow, caring relationship flow, and information flow.

Design: Descriptive study.

Methods: A questionnaire including demographics and questions about continuity of care was completed by 83 of the 120 eligible nurses (response rate, 69\%) in one hospital district in Finland.

Findings: According to the nurses, continuity of patient care is mostly well realized. On the day of surgery, information flow was the domain that was best realized. In the opinion of the nurses, continuity of care was least realized at home before surgery and at home during the period after surgery. Conclusions: Based on nurses' perceptions, continuity of care was relatively well realized.
\end{abstract}

Keywords: nurses' perceptions, continuity of care, day surgery, ambulatory surgery.

(C) 2016 by American Society of PeriAnesthesia Nurses

THE SIGNIFICANT INCREASE in the number of day surgery procedures has brought new kinds of challenges to patient care and its continuity. To ensure the continuity of care, the development of day surgery practice calls for regional collaboration, such as between primary care and specialized care. Day surgical care provides clear benefits for the health care organization, ${ }^{1}$ and patients and staff have also been satisfied with day surgical care. ${ }^{2}$

Nurses working in day surgery units need to know and understand the entire pathway of the day surgi- cal patients to be able to improve, support, and confirm the continuity of care. However, based on previous studies, this is not always the case. ${ }^{3,4}$ To ensure continuity of care, nurses and other health care professionals have to consider patient care as a whole throughout the day surgery experience. ${ }^{5}$

Nurses make up a large professional group with a significant task to ensure high-quality patient care and continuity of care. Studying nurses' perceptions of the realization of continuity of patient care in day surgery is therefore well motivated. In

\footnotetext{
Marja Renbolm, PbD, RN, MNSc, is the Nursing Director, Department of Emergency Medicine and Services, University of Turku, Hospital District of Helsinki and Uusimaa, Finland; Tarja Suominen, PbD, RN, is a Docent Professor, University of Turku, University of Tampere, Finland; Pauli Puukka, MSocSc, is a Senior Planning Officer, National Institute for Health and Welfare, Turku, Finland; and Helena Leino-Kilpi, PbD, RN, is a Professor, University of Turku, and Nurse Director, Turku University Hospital, Finland.
}

\footnotetext{
Conflict of interest: None to report.

Address correspondence to Marja Renbolm, Department of Medicine, Helsinki University Central Hospital, Meilabti Hospital, PO Box 340, O0029 Helsinki, Finland; e-mail address: marja.renbolm@bus.fi.

(C) 2016 by American Society of PeriAnestbesia Nurses 1089-9472/\$36.00

bttp://dx.doi.org/10.1016/j.jopan.2015.08.013
} 
this study, continuity of care is the connectedness between different stages in the health care system among the patient, health care professionals, and the organization. Continuity of care is defined as a health care process taking place in time (time flow), requiring co-ordination (co-ordination flow), rapport (caring relationship flow), and information (information flow). ${ }^{3,4}$ Time flow describes the treatment over time; it is the care process carried out within a certain time. Co-ordination flow describes the fluency of treatment and to that the care works well. Caring relationship flow describes the course of relationships in care. Information flow describes the flow of information and how the patient receives information. ${ }^{4}$

\section{Literature Review}

A search for the relevant literature was conducted in the Ovid MEDLINE, CINAHL, and Cochrane databases with the search words continuity of care, nurses' perceptions/experiences, day surgery/ ambulatory surgery/day surgical procedures, time flow, coordination flow, caring relationship flow, and information flow. The articles included had to be written in English and published in 1996 to 2014 period. In later paragraphs, the results are described according to the flows mentioned earlier.

Time flow is a patient care process carried out within a certain time frame. ${ }^{4}$ When evaluating time flow from nurses' perspective, it is important that nurses understand and consider that waiting is not an activity well received in today's fast-paced society. ${ }^{5}$ Nurses need to value patients' time and inform patients within admission of the expected surgical time and potential delays. ${ }^{6}$ From the patient's viewpoint, the wish of getting the operation done as quickly as possible is emphasized in time flow. Patients have been dissatisfied with the waiting times for surgery. ${ }^{5,7}$

Co-ordination flow is the fluency of patient treatment during different phases. Day surgical care is realized among the patient, health care professionals, and the organization. ${ }^{4}$ From the point of view of the organization, development of day surgery activities calls for regional and local collaboration between specialized care and primary care to ensure the continuity of care. From the perspective of health care professionals, previous studies have underlined the importance of preoperative collaboration, for example, between nurses working in health care centers and the hospital in assessing patients before the operation ${ }^{8}$ and in home care after surgery. ${ }^{9}$ Because of the short time patients spend in hospital, the roles of nurses involved in day surgery co-ordination differ from those in traditional surgery. Because of the reasons given previously, from the patients' point of view, the role of self-care has also grown in importance both before and after surgery, ${ }^{10-13}$ as has that of care provided by family and friends. ${ }^{14}$

Caring relationship flow refers to rapport between health care professionals and patients at different phases of care. ${ }^{4}$ From nurses' viewpoint, continuity means that professional nursing care becomes visible and that the pre-, intra-, and postoperative dialogs that the continuity creates can give meaning to their work. ${ }^{15}$ Caring relationship between the patient and the nurse requires that the nurse has had enough time on hand to build the caring relationship. ${ }^{16}$ Because of the limited time that patients spend in the day surgery unit, barriers for developing therapeutic relationship between the nurse and the patient are present. ${ }^{6}$ In caring relationships, the so-called unsatisfactory encounters focus on hurried interactions. ${ }^{5}$ As evaluated by nurses who work in day surgery units, patients' and family members' expectations of the day surgery nursing relationships are not always met. ${ }^{17}$ Shortcomings in the caring process can easily be mended by nurses and other health care professionals; by using perioperative dialog, they could create continuity for patients and themselves in the pre-, intra-, and postoperative phases. ${ }^{18}$ Patients want to know the nurse who will look after them in the hospital before the day of surgery and to have an opportunity to meet the same nurse even after the operation. ${ }^{4,19}$ According to previous studies, patients also value highly the relationship with the physician. ${ }^{20}$ Patients want to meet the treating surgeon before the operation ${ }^{21}$ and after it. ${ }^{4}$

Information flow involves patients' fluent receipt of knowledge on their care in different phases of day surgery. ${ }^{4}$ Several researchers have studied nurses' perceptions of preoperative teaching. ${ }^{22}$ In the study by Tse and $\mathrm{So}^{22}$ a discrepancy was found between nurses' perceptions and caring practice in relation to the provision of preoperative information. Nurses' perceptions about 
preoperative teaching directly affect their practice in providing it. Limited teaching aids, tight operation schedules, and language barriers diluted the delivery of preoperative information to ambulatory surgery patients. ${ }^{22}$ There are study results from the patient's viewpoint arguing that surgical patients received less knowledge than they felt they expected on the biophysiological, functional, experiential, ethical, social, and financial dimensions. ${ }^{23}$ The results of a study by Leino-Kilpi et $\mathrm{al}^{24}$ showed that patients seem to receive most knowledge in the biophysiological domain. On the other hand, patients with higher preferences seem to receive less knowledge than those with lower preferences. ${ }^{24}$ The provision of information concerning the operation, especially anesthesia, has been perceived as insufficient by patients. Sufficient provision of information is associated with knowledge of the caring staff and meeting them before the operation. $^{25}$ The recuperation phase at home has also been shown to involve a number of challenges. The postoperative recovery at home implies many responsibilities for patients. ${ }^{13}$ Patients have also felt that they receive inadequate information because of limited access to health care professionals. ${ }^{9}$ Patients need appropriate information, ensuring that support and advice is easily accessible for the patients who need it $^{26}$ so that they can take care of themselves.

\section{Methods}

\section{Aim, Sample, and Data Collection}

The purpose of this study was to analyze nurses' perceptions of the realization of continuity of care in day surgery. The data were collected from the largest hospital district in Finland (out of 20) between December 2009 and 2010. The study population ( $N=120)$ consisted of nurses working in the day surgery units of five different hospitals in this hospital district. The nurses taking part in the study were involved in the care of surgical patients in day surgery units. The final response rate for the nurses was $69 \%(n=83)$.

All units were personally informed by the researcher (MKR). The questionnaires were handed out to the ward managers and distributed by them (or persons assigned by them) to the nurses working in the day surgery units. The questionnaires were returned to the unit in sealed envelopes.

\section{Instrument}

Data were collected with a questionnaire developed for this study because there was no existing instrument usable for this study. The content of the questionnaire was based on the literature and an interview study with patients. ${ }^{3}$ The questionnaire was piloted in one Finnish central hospital (not the same hospital district where the main data were collected) among 20 nurses working in a day surgery unit. Pilot testing showed that the questions were understandable, easy to respond, and time needed for responding was reasonable. No changes to the questionnaire were needed. The questionnaire consists of 33 Likert-scale items $(1=$ strongly disagree and $5=$ strongly agree). Continuity of care was divided into four different categories: timing of care (nine items), co-ordination of care (nine items), caring relationship in care (six items), and information on care (nine items). The questionnaire was used to elicit nurses' perceptions of the continuity of patient care. The questionnaire included 18 items of background factors, seven items of sociodemographic background (age, gender, education in health care, job situation, length of work experience, length of working in the present workplace, and work tasks), seven items of preoperative preparation for the operation (first visit to health care, care in outpatient clinic, preoperative visit, preoperative clinic, knowledge of attending nurse, surgeon, and anesthesiologist, waiting time, and expected waiting time), and four items about postoperative care (convalescence time, postoperative call, patient's need for further information, postoperative meeting with the nurse, surgeon, and anesthesiologist in the day surgery unit).

\section{Etbical Considerations}

The research adhered to the general principles of research ethics. ${ }^{27}$ The study plan was approved by the ethics committee of the hospital district. Permission to collect the data was received from the authorities at the five hospitals. Nurses' consent to participate was assumed by return of the completed questionnaires. The subjects could also return an empty questionnaire. The subjects answered anonymously, and their identity was not revealed to the researcher. 


\section{Data Analysis}

The data were analyzed statistically using SPSS software for Windows (version 17.0; SPSS, Inc., Chicago, IL) and SAS (version 9.1; SAS Institute, Inc., Cary, NC). The data were described by using frequency tables and descriptive statistics. Four sum variables were formed: time flow, co-ordination flow, caring relationship flow, and information flow. The scales of some items were reversed before forming the sum variables. The four sum variables mentioned previously were finally combined into a total sum variable. The consistency of these sum variables was estimated by calculating Cronbach's alpha coefficients. The alpha coefficients ranged from 0.67 to 0.82 (time flow, 0.67 ; co-ordination flow, 0.70 ; caring relationship flow, 0.70; and information flow, 0.82). Alpha of the sum variable total continuity of care was 0.89. Unfortunately, factor analysis to explore the construct validity of the instrument was not allowed by the number of observations.

Comparisons between the sum variables were made by repeated-measures analysis of variance and confirmed by Wilcoxon signed rank test because of some skewed distributions. Pearson and Spearman correlations were used to examine the interdependencies between the sum variables. Multivariate analyses were done to identify the independent determinants of the continuity of care. First, significant background variables were found for each sum variable by Pearson and Spearman correlations, $t$ test, or analysis of variance. Then, all univariately significant background variables were included in the multivariate regression model and were removed stepwise one by one until all determinants in the model were statistically significant. The level of significance was set at $P<.05$.

\section{Results}

\section{Background Factors}

Most nurses (92\%) taking part in the study were females, with a mean age of 44.2 years (range, 23 to 61). Eighty-eight percent of the respondents had a permanent job. The work tasks of nearly all respondents (91\%) included pre-, intra-, and postoperative patient care, whereas the remaining nurses worked as so-called queue nurses, who informed patients of their scheduled surgery time and made sure patients have written guidance preoperatively (Table 1 ).

The nurses were also asked about their views concerning the realization of the patient pathway of day surgical patients, that is, how, in their opinion, patients are able to access care, how care guidance is realized at different stages, and whether patients know the staff treating them (the nurse, operating surgeon, and anesthesiologist). In Finland, there are guaranteed statutory time frames for access to treatment, and we wanted to know if these time frames realize in real practice, as seen by nurses.

Table 1. Sociodemographic Data

\begin{tabular}{|c|c|c|c|c|}
\hline \multirow[b]{2}{*}{$\begin{array}{l}\text { Sociodemographic } \\
\text { Variables }\end{array}$} & \multicolumn{4}{|c|}{ Nurses $(N=83)$} \\
\hline & $\begin{array}{c}\text { Mean } \\
\text { (Standard } \\
\text { Deviation) }\end{array}$ & $\mathbf{n}$ & $\%$ & Range \\
\hline \multicolumn{5}{|l|}{ Gender } \\
\hline Male & & 7 & 8 & \\
\hline Female & & 76 & 92 & \\
\hline Age & $44.2(9.7)$ & 79 & & 23 to 61 \\
\hline Younger than $30 \mathrm{y}$ & & 6 & 7 & \\
\hline 30 to $40 y$ & & 20 & 24 & \\
\hline 41 to $50 \mathrm{y}$ & & 31 & 38 & \\
\hline Older than $50 \mathrm{y}$ & & 28 & 30 & \\
\hline \multicolumn{5}{|l|}{ Education } \\
\hline Nurse & & 22 & 27 & \\
\hline Specialized nurse & & 35 & 42 & \\
\hline $\begin{array}{l}\text { Nurse, bachelor } \\
\text { of nursing }\end{array}$ & & 21 & 25 & \\
\hline $\begin{array}{l}\text { Master of health } \\
\text { science }\end{array}$ & & 2 & 2 & \\
\hline Other & & 3 & 4 & \\
\hline \multicolumn{5}{|l|}{ Current position } \\
\hline Permanent & & 73 & 88 & \\
\hline Locum & & 10 & 12 & \\
\hline \multicolumn{5}{|l|}{$\begin{array}{l}\text { Duration of work } \\
\text { experience }\end{array}$} \\
\hline 0 to $5 \mathrm{y}$ & & 10 & 13 & \\
\hline 6 to $15 y$ & & 29 & 37 & \\
\hline$>15$ & & 40 & 50 & \\
\hline \multicolumn{5}{|l|}{$\begin{array}{l}\text { Duration of work } \\
\text { experience in } \\
\text { current job }\end{array}$} \\
\hline$<1 \mathrm{y}$ & & 7 & 8 & \\
\hline 1 to $3 y$ & & 22 & 27 & \\
\hline 4 to $10 y$ & & 37 & 45 & \\
\hline 11 to $37 \mathrm{y}$ & & 17 & 20 & \\
\hline
\end{tabular}


There was a high variation in nurses' responses referring to admittance to care, preoperative discussion at the day surgical unit, and the contact by phone after the operation showed great variation. It can therefore be assumed that the practices vary between hospitals. Nearly half of the respondents considered that patients have a need of further guidance after the operation.

\section{Realization of Continuity of Care}

Continuity of patient care is well realized (M, 3.91; $\mathrm{SD}, 0.47)$, as seen by nurses. The highest mean value was seen in information flow (M, 3.96; SD, $0.60)$. There were some differences between the mean values of the flows, but they were not statistically significant. The lowest mean value was seen in co-ordination flow (M, 3.86; SD, 0.53) (Table 2).

Particularly on the day of the operation, continuity of patient care is well realized. Information flow was best realized (M, 4.7). However, there is still room for improvement. The variable that was least realized was caring relationship flow; nurses managing patients' affairs before the operation (M, 2.6). In the case of time flow, patients have to wait for admittance to surgery at the day surgery unit. In the case of co-ordination flow, places that provide care do not always engage in systematic cooperation preoperatively and postoperatively. When it comes to information flow, patients should be more active in seeking information.

\section{Realization of Continuity of Care in Relation to Background Factors}

The realization of continuity of care was associated with background factors. Statistically significant associations were found between background factors and continuity of care in terms of continuity of care as a whole, as well as the four domains: time flow, co-ordination flow, caring relationship flow, and information flow. The univariate correlations between background variables and the continuity of care and its subcategories varied between 0.23 and 0.40 , all significant at least at level .05 . In addition, some associations had significant $U$ shape (Table 3). Age, length of work experience, patient guidance, meeting with treating staff, and work tasks were associated with nurses' perception of the realization of continuity of patient care. Age has a positive effect on the realization of time flow and co-ordination flow, meaning that the older the respondent, the better these were realized. The length of working experience had an impact when assessing the realization of time and co-ordination flow. The longer the nurses had been working, the poorer was their assessment concerning the realization of the aforementioned flows. In the case of caring relationship flow, the finding was opposite: the longer the nurses had been working, the better they thought that the caring relationship was realized. If the patient needs more guidance after the surgery, the time and information flows are impacted. Meeting the nurse after the operation had a positive impact

Table 2. The Sum Variables on Continuity of Care

\begin{tabular}{|c|c|c|c|c|c|c|c|c|}
\hline \multirow[b]{2}{*}{ Sum Variable $\dagger$} & \multirow[b]{2}{*}{$\mathbf{n}$} & \multirow[b]{2}{*}{$\begin{array}{c}\text { Mean } \\
\text { (Standard } \\
\text { Deviation) }\end{array}$} & \multirow[b]{2}{*}{ Median } & \multirow[b]{2}{*}{ Range } & \multirow[b]{2}{*}{ Alpha } & \multicolumn{3}{|c|}{$\begin{array}{l}\text { Spearman Correlations } r_{\text {s }} \\
\text { Between the Sum Variables }\end{array}$} \\
\hline & & & & & & $\begin{array}{l}\text { Time } \\
\text { Flow }\end{array}$ & $\begin{array}{l}\text { Co-ordination } \\
\text { Flow }\end{array}$ & $\begin{array}{c}\text { Caring } \\
\text { Relationship } \\
\text { Flow }\end{array}$ \\
\hline Information flow & 83 & $3.96(0.60)$ & 4.00 & 2.56 to 5.00 & 0.82 & $0.52 \ddagger$ & $0.65 \ddagger$ & $0.38 \ddagger$ \\
\hline Time flow & 83 & $3.92(0.54)$ & 3.88 & 2.89 to 5.00 & $0.67 \ddagger$ & - & & \\
\hline $\begin{array}{l}\text { Caring relationship } \\
\text { flow }\end{array}$ & 83 & $3.90(0.73)$ & 4.00 & 1.67 to 5.00 & 0.70 & $0.40 \ddagger$ & $0.43 \ddagger$ & - \\
\hline Co-ordination flow & 81 & $3.86(0.53)$ & 3.89 & 2.67 to 4.89 & 0.70 & $0.58 \ddagger$ & - & \\
\hline $\begin{array}{l}\text { Total continuity } \\
\text { of care }\end{array}$ & 81 & $3.91(0.47)$ & 3.94 & 2.97 to 4.82 & 0.89 & & & \\
\hline
\end{tabular}

*All correlations are significant.

${ }^{\dagger}$ All pair-wise differences between the four sum variables are nonsignificant.

${ }^{\ddagger} P<.001$. 
on time flow, co-ordination flow, caring relationship flow, and information flow. Nurses who were involved in actual intraoperative patient care but were working as so-called queue nurses considered that co-ordination flow was realized significantly better compared with those taking part in intraoperative care (Table 3).

\section{Discussion}

The purpose of this study was to analyze nurses' perceptions of the realization of continuity of care in day surgery. Based on nurses' perceptions, continuity of care was relatively well realized in all domains of continuity of care. Information flow was best

\section{Table 3. Association of Subcategories of Continuity of Care With Background Variables From} Nurses' Viewpoint

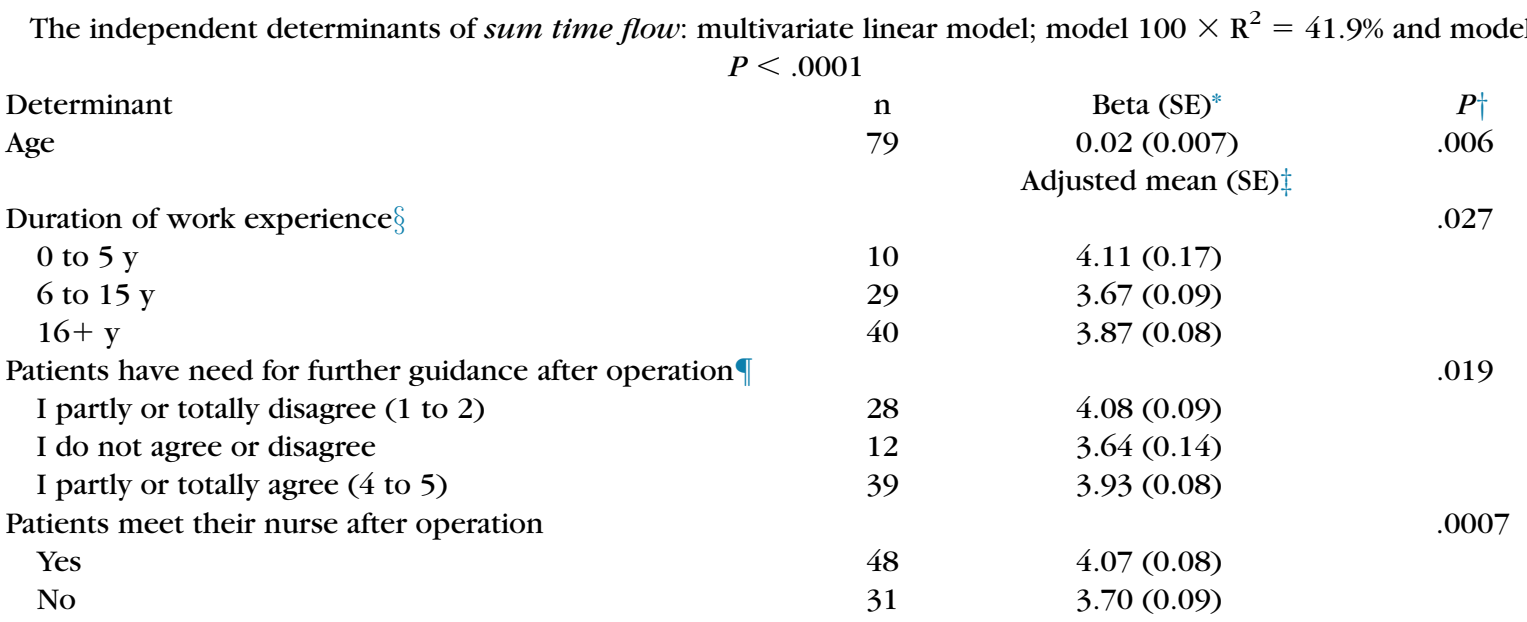

The independent determinants of sum co-ordination flow: multivariate linear model; model $100 \times \mathrm{R}^{2}=30.6 \%$ and model $P<.0001$

$\begin{array}{lcr}\begin{array}{l}\text { Determinant } \\ \text { Age }\end{array} & \mathrm{n} & \begin{array}{c}\text { Beta (SE)* } \\ 0.03(0.007)\end{array} \\ & 80 & \begin{array}{r}\text { Adjusted mean (SE } \\ \text { Duration of work experience } \|\end{array} \\ \quad 0 \text { to } 5 \mathrm{y} & 10 & 4.39(0.19) \\ 6 \text { to } 15 \mathrm{y} & 29 & 4.15(0.12) \\ \quad 16+\mathrm{y} & 41 & 3.88(0.11) \\ \text { Work tasks in patient intraoperative care } & & \\ \quad \text { Yes } & 73 & 3.89(0.07) \\ \text { No } & 7 & 4.40(0.18) \\ \text { Patients meet their nurse after operation } & & 4.28(0.11) \\ \quad \text { Yes } & 49 & 4.00(0.12) \\ \text { No } & 31 & \end{array}$

The independent determinants of sum caring relationship flow: multivariate linear model; model $100 \times \mathrm{R}^{2}=12.4 \%$ and model $P=.015$

\begin{tabular}{lcr}
$\begin{array}{l}\text { Determinant } \\
\text { Duration of work experience }{ }^{* *}\end{array}$ & $\mathrm{n}$ & Adjusted mean (SE) \\
0 to $5 \mathrm{y}$ & 11 & $3.83(0.21)$ \\
6 to $15 \mathrm{y}$ & 42 & $3.62(0.13)$ \\
$16+\mathrm{y}$ & 29 & $4.05(0.11)$ \\
Patients meet their nurse after operation & & \\
Yes & 50 & $4.00(0.11)$ \\
No & 32 & $3.66(0.13)$ \\
\hline
\end{tabular}


Table 3. Continued

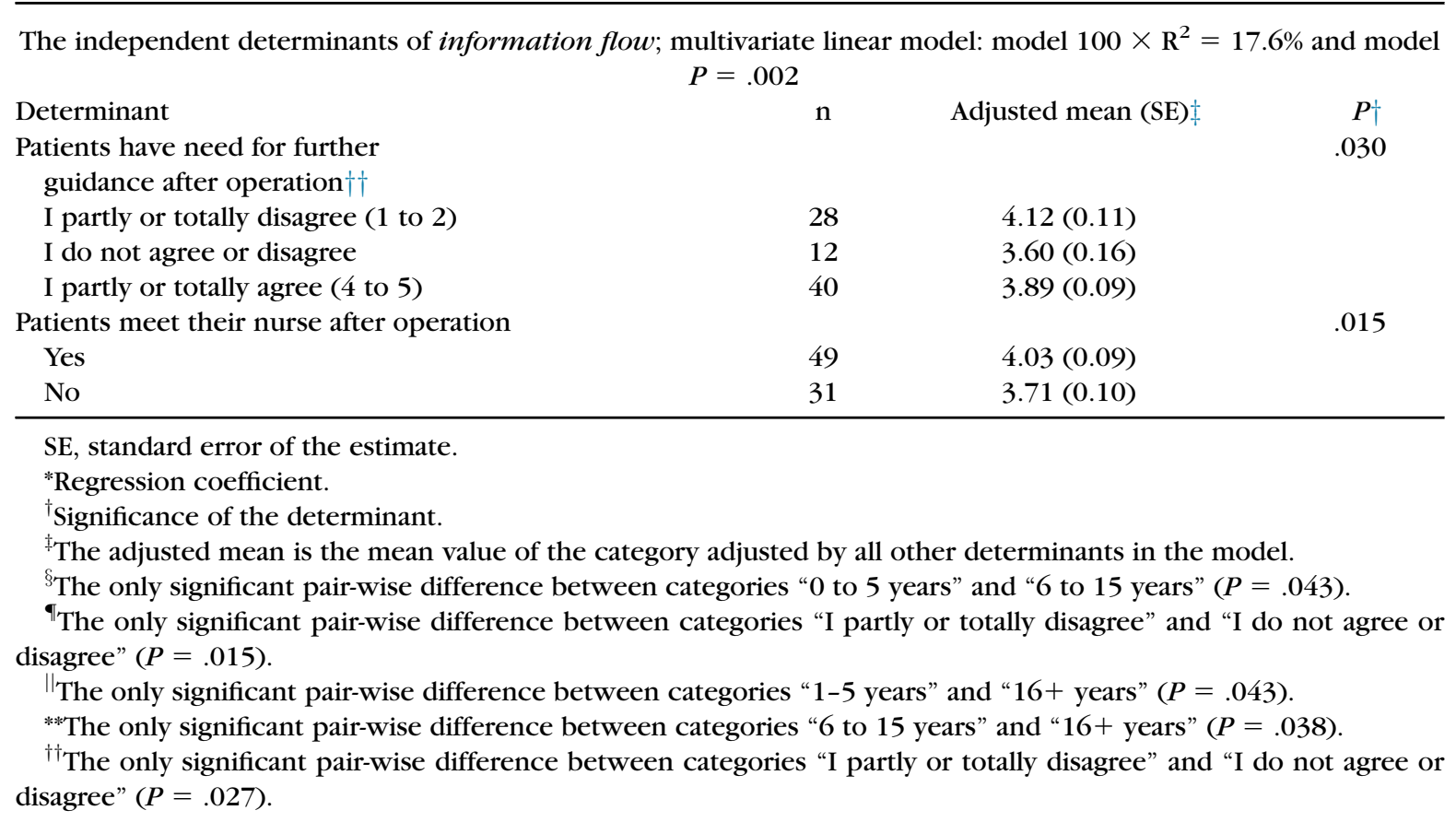

realized in care continuity, whereas continuity of care before and after surgery was most poorly realized.

\section{Realization of Continuity of Care}

In terms of the realization of time flow, the respondents thought that patients had to wait too long for preoperative preparations and admittance to surgery. The nurses thought that on the day of surgery, patients had to wait longer than at home before or after surgery. Similar findings have been reported in previous studies. Patients have been particularly dissatisfied with the waiting preceding surgery. ${ }^{5,7}$ One of the primary complaints of same day surgery patients has been the length of waiting time in day surgical units. To improve the continuity of care, it is important that nurses keep patients up to date with regard to the expected surgical time and potential delays. ${ }^{6}$

In the realization of co-ordination flow, coordination of care works well on the day of the operation but not in terms of collaboration between different places of care before the operation and after the operation. In their findings, Moss and $\mathrm{Xiao}^{8}$ underlined the importance of collaboration between the health care center and hospital. This collaboration and the fact that it is brought to the patients' attention have been shown to be important in the postoperative period as well, particularly information about contacts in the case of problems. ' Nurses have to be aware of the patient's day surgical pathway; this way, they are better able to support the continuity of care..$^{3,4}$

In the realization of caring relationship flow, nurses do not take on managing patients' affairs before the day of the operation. Responsibility for patients' care before the operation is unclear. According to previous studies, shortcomings in the care process could be amended by nurses through perioperative dialog in the pre-, intra-, and postoperative phases. ${ }^{18,19}$ When nurses use the so-called perioperative dialog, they can create continuity to patients and themselves. In the opinion of nurses, patients' and their relatives' expectations concerning the caring relationship are not always realized, either. ${ }^{17}$ Preoperatively, patients are not necessary aware of the professionals responsible. However, previous research has shown that this is important for a positive experience of realization of continuity of care among patients. ${ }^{4,18}$ One recommendation has been that 
nurses responsible for the care of the patient during the operation should meet the patient both before and after the operation. ${ }^{16}$ In earlier studies, patients have considered their wish to meet the operating surgeon as important ${ }^{21}$; a postoperative meeting with the surgeon has also been considered to have a positive effect on the continuity of care. ${ }^{4}$ In this study, two of three respondents thought that patients know the surgeon performing the operation before the day of the operation.

In the realization of information flow, continuity of care may be improved postoperatively, for example, by calling the patients at home..$^{21,28}$ Less than half of the patients were contacted via phone the day after the operation. There is evidence suggesting that a postoperative followup call by a nurse is of direct benefit in the form of better patient outcomes, resulting in less distress and better physical and mental health states. ${ }^{29} \mathrm{~Pa}$ tients have also expressed a wish for better and more intensive postoperative follow-up by the surgical unit ${ }^{16}$ as well as easier access to health care professionals.' Practices of preoperative followup seem to vary between hospitals. On the other hand, previous research findings show that this practice has a significant positive effect on improving continuity of patient care. Based on their findings, Fraczyk and Godfrey ${ }^{30}$ recommended sending patients to preoperative assessment immediately after their outpatient consultation, which would also provide more seamless service, promoting increased patient satisfaction levels. A nurse-led preassessment clinic also appeared to have a strikingly positive impact on the patients: they received person-centered care and felt they were better informed about the surgery and well prepared for admission. ${ }^{31}$

\section{The Association of Background Factors in the Realization of Continuity of Care}

In the study data, nurses' assessment of the realization of continuity of care (time flow and coordination flow) seemed to be improved by nurses' age, but on the other hand, shorter working experience was associated with more positive assessments. However, the highest assessment associated with caring relationship flow was given by those with the longest work experience. As a cautious conclusion, it could be suggested that older nurses are more intimately acquainted with the of day surgery pathway and therefore consider it better realized. In previous research, meeting with the nurse after the operation has been shown to be important for a positive experience of realization of continuity of care. ${ }^{4,18}$ It has also been recommended that the nurse taking care of the patient during the operation should also meet the patient before the operation. ${ }^{16}$

An interesting finding was that continuity (time flow and information flow) was perceived as poorest by the respondents who had no clear opinion of patients' need of further guidance. As a cautious conclusion, it might be presumed that the nurses in question have an unclear perception of continuity of care. In some cases, patients were also unable to remember the guidance. ${ }^{28}$ On the other hand, nurses' limited teaching aids, language barriers, and lack of time had prevented nurses from giving postoperative guidance to day surgical patients. $^{22}$ It has also been pointed out by nurses that active implementation of telephone call service is hampered by lack of information and time on the part of nurses. ${ }^{32}$

According to research findings, continuity (coordination flow) was perceived as better if intraoperative care was not a part of the respondent's duties as opposed to those who were involved in it. This finding is explained by the fact that the nurses who did not work with intraoperative care were so-called queue nurses, meaning that they were involved in surgery queue management, not practical nursing care. As a result, they may assess the realization of co-ordination to be better.

\section{Limitations and Strengths of the Study}

Limitations and strengths in this study have to do with the sample and instrument. The data were gathered from five different hospitals in the largest of the 20 hospital districts in Finland. The nurses involved in the care of day surgical patients were included in the study sample, and the subjects worked in units that were as similar as possible. The sample was not very large $(\mathrm{N}=120)$. However, it may be considered as a strength that the final response rate was $69 \%$ $(n=83)$. The sample included all nurses working within one hospital district. According to 
post hoc power analysis, the power of finding a significant $5 \%$ difference between the subcategories of continuity of care with alpha $=0.05$ would be more than 0.80 . This may be regarded as a support for our sample size.

The researcher (MKR) made an attempt to select the contact persons so that they would be able to provide information about the study to others. The response rate could have been higher (albeit good). The nurses responded to the survey while at work, during working time. It can be assumed that not all nurses had a possibility to answer the survey because of lack of time or timing of data collection, and others. Another limitation of this study is that it was conducted with quite a small number of nurses in one country. The nurses responded to the survey from a Finnish perspective, and the findings cannot therefore be directly generalized to other countries. However, day surgery is organized very much according to the same principles internationally, meaning that some of the findings may be used in other countries in an indicative capacity. In future, more generalizable knowledge is needed to develop continuity of patient care further. A larger sample would have enabled examination of the instrument's construct validity using factor analysis, for example. On the other hand, the group of respondents and data may be considered sufficiently representative as statistically significant, and relevant findings were obtained.
Content validity of the instrument was based on the literature and an interview study. ${ }^{3}$ Reliability, measured by Cronbach's alpha, indicated good consistency. ${ }^{33}$ The Cronbach alpha coefficients for the scales ranged from 0.67 to 0.82 and alpha for the total sum continuity of care was 0.89 . For a new instrument, these alpha levels may be considered adequate.

\section{Conclusions}

According to this study, continuity of care of day surgery patients is realized rather well. The best realization was seen on the day of the surgery. There are still areas that should be developed further. The nurses considered that continuity of care was most poorly realized at home before and after surgery.

The present study focused on the service system. Nurses' perceptions of the continuity of care are of significance, particularly knowledge that in their view, time flow, co-ordination flow, and caring relationship flow should be improved both before and after the operation day. If the aim is to improve the continuity of care, an effort must be made to focus on increasing nurses' knowledge on the elements of continuity of care and the patient care chain. In this study, the continuity of care was investigated from the viewpoint of nurses working in day surgical units. Nurses' perceptions of the continuity of care at different phases of the care chain would be interesting topic for further research.

\section{References}

1. Available at: www.euro.int/_data/assets/pdf_file/0011/ 108965/E90295.pdf. Accessed November 28, 2014.

2. Mattila K. Day surgery in Finland: randomized and cross-sectional studies on treatment, quality, and outcome. Academic dissertation. Finland: Helsinki University; 2010.

3. Renholm M, Suominen T, Turtiainen AM, Leino-Kilpi H. Continuity of care in ambulatory surgery critical pathwaysThe patients' perceptions. Medsurg Nurs. 2009;18:169-173.

4. Renholm M, Suominen T, Turtiainen AM, Puukka P, LeinoKilpi H. Continuity of care in day surgical care-Perspective of patients. Scand J Caring Sci. 2014;28:706-715.

5. Gilmartin J, Wright K. Day surgery: Patients' felt abandoned during the preoperative wait. J Clin Nurs. 2008;17:2418-2425.

6. Freeman K, Denham SA. Improving patients' satisfaction by addressing same day surgery wait times. J Perianesth Nurs. 2008;23:387-393.
7. Leddy KM, Kaldenberg DO, Becker BW. Timeliness in ambulatory care treatment. J Ambul Care Manage. 2003;2: 138-149.

8. Moss J, Xiao Y. Improving operating room: Communication pattern assessment. J Nurs Adm. 2004;34:253-259.

9. Mitchell M. Literature review: Home recovery following day surgery. Ambul Surg. 2013;19:13-27.

10. Gilmartin J, Wright $\mathrm{K}$. The nurse's role in day surgery: A literature review. Int Nurs Rev. 2007;54:183-190.

11. Mitchell M. Nursing intervention for day-case laparoscopic cholecystectomy. Nurs Stand. 2007;22:35-41.

12. Bellani ML. Psychological aspects in day-case surgery. Int J Surg. 2008;6:44-46.

13. Berg K, Arestedt K, Kjellgren K. Postoperative recovery from perspective of day surgery patients: A phenomenographic study. Int J Nurs Stud. 2013;50:1630-1638. 
14. Majholm B, Esbensen B, Thomsen T, Enbaek J, Möller A. Partners' experiences of the postdischarge period after day surgery-A qualitative study. J Clin Nurs. 2012;21:2518-2527.

15. Lindwall I, VonPost I, Eriksson K. Journal of Advanced Perioperative Care. 2007;3:3-10.

16. Bäckström S, Wynn R, Sorlie T. Coronary bypass surgery patients' experiences with treatment and perioperative care-A qualitative interview-based study. J Nurs Manag. 2006;14:140-147.

17. Majasaari H, Paavilainen E, Åstedt-Kurki P. The visible and invisible family: Nurses' perceptions of counselling in day surgical nursing. J Adv Perioper Care. 2007;3:11-19.

18. Lindwall L, Von Post I. Continuity created by nurses in perioperative dialogue-A literature review. Scand J Caring Sci. 2009;23:395-401.

19. Rudolfsson G, Von Post I, Eriksson K. The expression of caring within the perioperative dialogue: A hermeneutic study. Int J Nurs Stud. 2007;44:905-915.

20. Pandhi N, SaultzJW. Patients' perceptions of interpersonal continuity of care. J Am Board Fam Med. 2006;19:390-397.

21. Barthelsson C. Laparoscopic cholecystectomy. Patients' experiences of self-reported symptoms, perception of health and sense of coherence in short and long term perspective. Department of Clinical Science, Intervention and Technology. Academic dissertation. Stockholm, Sweden: Karolinska Institutet; 2009.

22. Tse KY, So WK. Nurses' perceptions of preoperative teaching for ambulatory surgical patients. J Adv Nurs. 2008; 63:619-625.

23. Rankinen S, Salanterä S, Heikkinen K, et al. Expectations and received knowledge by surgical patients. Int J Qual Health Care. 2007;19:113-119.
24. Leino-Kilpi H, Heikkinen K, Hiltunen A, et al. Preference for information and behavioral control among adult ambulatory surgical patients. Appl Nurs Res. 2009;22:101-106.

25. Kanerva AM. Tietoinen suostumus päiväkirurgisen potilaan hoidossa (Informed consent in day surgery patients care). Academic dissertation. University of Turku. Turku, Finland: Innales Universitates Turkuensis, C248; 2006.

26. Davis RE, Vincent C, Henley A, McGregor A. Exploring the care experience of patients undergoing spinal surgery: A qualitative study. J Eval Clin Pract. 2013;19:132-138.

27. ETENE. Muistilista eettisten toimikuntien jäsenille ja tutkijoille (Checklist for members of ethical committees and researchers). 2012. Available at: http://www.tutkija.fi/c/ document_library/get_file?. October 19, 2014.

28. Dewar A, Scott J, Muir J. Telephone follow-up for day surgery patients: Patient perceptions and nurses' experiences. $J$ Perianesth Nurs. 2004; 19:234-241.

29. Jones D, Duffy ME, Flanagan J. Randomized clinical trial testing efficacy of a nurse-coached intervention in arthroscopy patients. Nurs Res. 2011;60:92-99.

30. Fraczyk L, Godfrey H. Perceived levels of satisfaction with the preoperative assessment service experienced by patients undergoing general anaesthesia in a day surgery setting. J Clin Nurs. 2010;19:2849-2859.

31. Gilmartin J. Day surgery: Patients' perceptions of a nurse preadmission clinic. J Clin Nurs. 2004;13:243-250.

32. Chen CH, Ma HJ, Yen M, Li SF, Liu LC. Evaluation of a telephone call service for ambulatory surgery patients in Taiwan. $J$ Nurs Care Qual. 2007;22:286-288.

33. Burns N, Grove SK. Understanding Nursing Research, 6th ed. Philadelphia, PA: Saunders; 2009. 